\title{
Ценностные аспекты корпоративного медиадискурса коммерческого предприятия
}

\author{
Семашкина Н.C. \\ Белгородский государственный национальный исследовательский университет, \\ Россия, 3008015, г. Белгород, ул. Победы, 85 \\ E-mail: pressasns@mail.ru
}

\begin{abstract}
Аннотация. Корпоративные медиа могут выступать в качестве эффективного канала репрезентации корпоративных ценностей коммерческого предприятия. Их тематическая направленность нередко ограничена рамками корпоративной информации, что определяет ключевые особенности аудиторных групп и вариантов подачи информации. Целью данного исследования является анализ аксиологической дифференциации корпоративного медиадискурса в зависимости от исторического контекста. Рассмотрены ценностные аспекты медиадискурса коммерческого предприятия на примере корпоративного издания завода «Белэнергомаш». Исследование проводилось на основе метода традиционного анализа документов, включивших в себя 179 выпусков издания за период с 1970 по 2019 годы. В результате были выявлены основные аксиологические модели корпоративного медиадискурса, реализуемые в издании: антропоцентрическая, ресурсоцентрическая и эффектоцентрическая. Было установлено, что в медиадискурсе издания в зависимости от исторически обусловленных экономических приоритетов компании доминировала определённая аксиологическая модель, а фокус репрезентации смещался от человека к ресурсам компании и коммерческому эффекту. Результаты исследования позволяют уточнить методологию анализа медиадискура корпоративных изданий и критерии ценностных моделей медиадискурса, а также вносят вклад в исследования внутренних коммуникаций компании и корпоративной культуры.
\end{abstract}

Ключевые слова: корпоративные медиа, ценности, корпоративные ценности, аксиологические модели.

Для цитирования: Семашкина Н.С. 2020. Ценностные аспекты корпоративного медиадискурса коммерческого предприятия. Вопросы журналистики, педагогики, языкознания, 39 (2): 159-168. DOI 10.18413/2712-7451-2020-39-2-159-168

\section{Value aspects of corporative media discourse of commercial companies}

\author{
Nadezhda S. Semashkina \\ Belgorod National Research University, \\ 85 Pobeda St, Belgorod, 308015, Russia \\ E-mail: pressasns@mail.ru
}

\begin{abstract}
Corporative media are regarded as an efficient channel for representing corporative values of commercial companies. Their topics are framed by the nature and features of corporative information, e.g. branch news, marketing information about goods and services, etc. It also determines the key dimensions of audience and target groups, and the ways to transmit the content. The researchers find it important to reveal the key tendencies of transformation of axiological models of corporative media of commercial companies in terms of the change of economical paradigm of inner communications. One of basic research and practical goals is to find the ways to minimize the tendencies of dehumanization of corporative media content. The goal of the paper is to reveal the axiological differentiation of corporative media discourse according to historical contexts. The research analyzes the axiological aspects of media discourse of commercial companies by the example of the corporative newspaper of the plant
\end{abstract}


"Belenergomash". Based on the method of traditional analysis of documents, the research comprised 179 issues of the newspaper from 1970 to 2019 . The results of the research revealed the key axiological models of the corporative media discourse of the newspaper: anthropocentric, resource-centric and efficiency-centric ones. The author claims that the axiological models dominated in the media discourse of the newspaper depending on the historically determined economic priorities of the company, while the focus of representation shifted from individuals to company resources and commercial effects. The research results contribute to the methodology of study of corporative newspapers discourse and axiological models of media discourse, and to the study of inner communications of companies and their corporate culture.

Keywords: corporative media, values, corporative values, axiological models.

For citation: Semashkina N.S. 2020. Value aspects of corporative media discourse of commercial companies. Issues in Journalism, Education, Linguistics, 39 (2): 159-168 (in Russian). DOI $10.18413 / 2712-7451-2020-39-2-159-168$

\section{Введение}

Корпоративные медиа традиционно рассматриваются в свете их коммуникационной и производственной функциональности [Лапина, 2004; Мурзин, 2005; Тухватова, 2007; Агафонов, 2008; Чемякин, 2011; Ромашова, 2015]. Общим является их трактовка как инструмента, обеспечивающего бесперебойную циркуляцию информационно-новостных потоков в компании, поддержки корпоративной культуры и повышения чувства лояльности к компании со стороны ее сотрудников [Гвозданная, 2011; Волкова, 2018], а также как маркетингового инструмента [Играев, 2012; Олтаржевский, 2013; Нариньяни, 2017]. Контент корпоративных изданий действительно формируется с учетом этих задач. В то же время нельзя игнорировать тот факт, что в основе селекции и редактирования материалов, предназначенных для размещения в корпоративных медиа, лежат не только прагматические, но и ценностные основания.

Нам представляется важным обратить внимание на аксиологическую дифференциацию корпоративного медиадискурса и его исторические формы. Аксиологические аспекты корпоративного медиадискурса не только репрезентируют базовые установки руководства корпорации относительно внутрикорпоративных отношений, но и могут выступать в качестве серьезного фактора имиджа компании, а также «корпоративного мировоззрения» ее сотрудников.

\section{Терминологические аспекты исследования}

Исследование ценностных аспектов корпоративного медиадискурса требует предварительно дать определение понятия «медиадискурс». По мнению А.В. Полонского, медиадискурс - это динамичная информационная среда, «внутри которой вызревает переживаемое и закрепляемое в сознании людей в виде поведенческих и нравственных эталонов знание о мире, социальных отношениях и идеологиях. В медиадискурсе собираются все идеи и слова, порождаемые обществом, и лишь затем - хотя и усиленным потоком - они возвращаются к нам» [Полонский, 2009, с. 152].

Т.Г. Добросклонская определяет медиадискурс в самом общем виде «как совокупность процессов и продуктов речевой деятельности в сфере массовой коммуникации во всем богатстве и сложности их взаимодействия» [Добросклонская, 2014, с. 152].

Два подхода к определению медиадискурса обозначает Е.А. Кожемякин [2010]. В первом случае исследователь предлагает считать медиадискурс специфическим типом речемыслительной деятельности, характерным только для информационного поля массмедиа. Согласно второму определению, это любой вид дискурса, реализуемый в поле массовой коммуникации и продуцируемый СМИ. Автор статьи разделяет вторую точку зрения и, соответственно, широко применяемую интерпретацию медиадискурса как «темати- 
чески сфокусированную, социокультурно обусловленную речемыслительную деятельность в масс-медийном пространстве» [Кожемякин, 2010, с. 14].

Под корпоративным медиадискурсом Н.В. Гвозданная понимает «уникальное явление, соединяющее личное обращение к читателям, предоставление отраслевой информации, продвижение торговой марки, развитие имиджа компании, при этом оно представляет собой неотъемлемый элемент программы формирования лояльности сотрудников в отношении деятельности компании» [Гвозданная, 2015, с. 214]. Л.В. Минаева [2018] обращает внимание на диалогические форматы корпоративного медиадискурса как эффективное средство трансляции корпоративных ценностей.

Далее приведем несколько распространенных определений понятия «корпоративные ценности». По мнению П.А. Сорокина, «именно ценность служит основой и фундаментом культуры» [1937, с. 67]. М.Г. Хасянова [2013] основной функцией ценностных ориентаций внутри компании называет регуляцию поведения сотрудников, поскольку они являются важным фактором индивидуальной и групповой мотивации. Корпоративные ценности, подчеркивает исследователь, являются таким регулятором только при условии, что они становятся личными ценностями сотрудника.

В.Г. Смирнова предлагает следующее определение: «ценности - ключевая переменная корпоративной культуры, переносимая из поколения в поколение и сохраняющая преемственность... Ценности организации основаны на знаниях и представлениях, которые рассматриваются ими в качестве нерасторжимых с существованием компании, придают значимость, смысл ее функционированию, ориентируют ее действия в изменяющейся среде» [Смирнова, 2014, с. 11]. Согласимся с этим определением и в рамках нашего исследования сделаем акцент на состоянии «переменчивости» (ключевая переменная; изменяющзаяся среда). Уточним, что ценности организации выражены в комплексе материальных ресурсов, к которым относятся, в том числе, и корпоративные медиа.

\section{Корпоративные ценности: теоретические рамки исследования}

Очевидно, что возникновение корпоративной прессы не было случайным явлением. По утверждению Д.Н. Мурзина [2007, с. 171], это стало ответом на потребность в новых формах коммуникации в условиях роста городов и промышленного производства. Необходимость передачи опыта и новых производственных знаний привела к возникновению первых фабричных и заводских изданий, ориентированных на сотрудников предприятия (современные издания формата b-2-pbusiness-to-personnel). А введение понятия корпоративных ценностей связано с аксиологизацией управления - имеется в виду использование ценностей в процессе руководства организацией.

По мнению А.И. Пригожина, «ценности есть такие представления о совершенстве чего-то значимого, на которые постоянно ориентируются те, кто к такому совершенствованию стремятся. Иначе говоря, это глубинные векторы жизнедеятельности, направляющие активность людей на всех ее вторичных, третичных и т. д. уровнях» [Пригожин, 2007, c. 3]. Примем данное определение как базовое.

А.И. Пригожин [2010, с. 37] выделяет несколько групп корпоративных ценностей:

1) ценности порядка (пунктуальность, дисциплина, управляемость, стабильность, безопасность, ответственность, согласованность и т. д.);

2) ценности развития (достижительность, инновационность, проактивность, конкурентность, креативность, клиентоориентированность, профессионализм, качество, эффективность, лидерство на рынке, синергия, стратегичность, целеустремленность, карьера, темп и т. д.);

3) ценности отношенческие (командность, взаимная обязательность, доверие, состязательность, уважительность, доброжелательность, демократизм, достоинство, открытость, честность и т. д.); 
4) ценности благополучия (доходность, благосостояние, семья, природа, комфорт, здоровье, безопасность, образование, интересная работа, лояльность, бесконфликтность и т. д.);

5) ценности социальные (польза обществу, социальная ответственность, добрый след в жизни и т. д.).

Как считает исследователь, их можно перераспределять (на экономические, моральные, поведенческие, гражданские, профессиональные, художественные и др.). Некоторые, безусловно, могут дублироваться в разных группах ценностей.

\section{Объект и методы исследования}

Очевидно, что для своего процветания любая организация должна уметь адаптироваться к часто меняющимся условиям внешней среды. Меняющиеся внешние условия определяют и аксиологический характер медиаконтента корпоративных изданий. С целью выявления основных ценностных моделей, использующихся в корпоративном медиадискурсе, нами было проведено исследование контента корпоративного издания крупного промышленного предприятия. На примере газеты завода «Белэнергомаш» рассмотрим подобные изменения в форме собственности предприятия, корпоративных ценностей и их репрезентации в медиа. Данная газета является достаточно типичной для всей категории корпоративных изданий в аспекте рубрикации, тематики, формата, периодичности, тиража и некоторых других значимых для корпоративных изданий параметров.

Нами проанализированы 52 номера газеты «Белгородский котельщик» за 1970 год, 47 номеров газеты «Трудовая слава» за 1999 год, 16 номеров газеты «Энергомаш» за 2003 год, а также выпуски современной газеты «Энергомаш» за 2014-2019 годы. Использованы метод традиционного анализа документов и метод сплошной выборки.

\section{Результаты исследования}

Первый номер корпоративной газеты «Белгородский котельщик» вышел в свет 5 ноября 1957 года. Издание являлось печатным органом партбюро, завкома и дирекции Белгородского котлостроительного завода. Под названием «Белгородский котельщик» газета выходила почти 20 лет. В 1977 году заводская газета изменила свое название и стала называться «Трудовая слава». Теперь это был печатный орган парткома, профкома, комитета ВЛКСМ и дирекции производственного объединения «Белгородский завод энергетического машиностроения».

В начале 2000-х экономическая ситуация в отрасли не лучшим образом сказалась на судьбе предприятия, и руководство «Энергомашкорпорации» приняло решение о закрытии нерентабельных объектов и организаций, в том числе корпоративных газет. Официально «Трудовая слава» перестала существовать в конце октября 2003-го.

В 2013 году руководством предприятия (ЗАО «Энергомаш (Белгород) - БЗЭМ», с августа 2014 года - ООО «Белэнергомаш - БЗЭМ») было принято решение о возобновлении выпуска корпоративной газеты под названием «Энергомаш». Первый ее номер увидел свет в октябре 2013 года.

Отметим, что во все периоды своего существования корпоративная газета стремилась освещать самые интересные новости, рассказывать о передовиках производства, перспективах развития завода и планах модернизации, участии в выставках и строительстве новых объектов. Соответственно, система ценностей предприятия репрезентируются в медиа через тематику, контекстуализацию с помощью визуальных средств, а также стилистических и риторических средств языка.

В разные исторические периоды можно говорить о преобладании той или иной аксиологической модели корпоративного медиадискурса: антропоцентрической (в центре которой - человек труда, передовики производства); ресурсоцентрической (вспомогательные средства, используемые при целевой деятельности сотрудников предприятия); техно- 
центрической (технологии, инновации); социоцентрической (солидарное общество, социум, трудовая этика и мотивация); эффектоцентрической (нацеленность на результат, коммерческий успех, производственные достижения и повышение конкурентоспособности предприятия). Уточним, что антропоцентрическая модель корпоративного медиадискурса, по нашему мнению, характерна для 1970-х годов, ресурсоцентрическая, техноцентрическая и социоцентрическая модели становятся преобладающими примерно с начала 1990-х годов, а эффектоцентрическая модель активно используется корпоративными медиа с 2010-х годов по настоящее время.

Обратим внимание на содержание первых полос газеты «Белгородский котельщик» за 1970-й год. В этот период газета выходит один раз в неделю (по пятницам) на четырех полосах формата А3. В течение года в свет вышли 52 номера заводской газеты, в 31 из них на первой полосе опубликованы материалы о передовиках производства. В процентном соотношении это составляет 59,6 \%. Иногда материалы публикуются под рубрикой «Люди нашего завода», чаще рубрика отсутствует, но форма подачи сохраняется: портрет на рабочем месте (фото) и несолько строк, рассказывающих непосредственно о самом человеке труда.

Обратимся к следующим примерам, репрезентирующим эту ценностную модель, характерным для указанного периода функционирования издания.

Пример 1. «Белгородский котельщик», № 8 (651) от 27 февраля 1970 года.

Труженики иееа № 22 взяли высокие сочиалистические обязательства в честь 100-летия со дня рождения В. И. Ленина. Сейчас, когда до юбилея осталось менее двух месяцев, они стараются работать как можно лучше.

На снимке: передовой слесарь-наладчик иеха № 22 Анатолий Санин на своем рабочем месте (фото В. Кузнецова).

На этом примере мы видим, что передовик представлен в качестве одного из работников завода, причем их деятельность характеризуется в возвышенно-положительной тональности («высокие обязательства», «работать лучше», «передовой») и помещена в государственно-идеологический макроконтекст, более абстрактный и общий, чем производственный контекст предприятия.

Пример 2. «Белгородский котельщик», № 13 (656) от 3 апреля 1970 года.

Всего год назад, после окончания Ленинградского политехнического института, пришел на завод Ахмед Даудович Хайбулаев. Свои знания, полученные в институте, молодой специалист успешно применяет на практике. Смена, где трудится Ахмед Даудович мастером участка опор, всегда справляется с производственными планами. На 120-130 прочентов выполняет она ежемесячно задания. Это отличный подарок 100-летию со дня рождения В. И. Ленина.

На снимке: А. Д. Хайбулаев (слева) и сварщик Н. Терещзенко (фото В. Кузнецова).

В примере 2 мы видим совмещение государственно-идеологического и производственного контекстов, однако акцент так же сделан на положительных характеристиках и достижениях конкретной личности - мастера участка.

Пример 3. «Белгородский котельщик», № 14 (657) от 10 апреля 1970 года.

Более 10 лет трудится в изехе № 20 крановщчица Валентина Ивановна Волобуева. На первый взгляд кое-кому может показаться, что профессия крановщика проста. Это не так. Вот, например, В. И. Волобуева работает на открытом воздухе. Это значит, что условия работы - трудные.

Валентина Ивановна отлично справляется со своими обязанностями.

На снимке: В. И. Волобуева (фото В. Кузнецова).

Пример 3 демонстрирует внимание редакции газеты к условиям труда крановщицы завода и положительно маркирует ее как работницу. В этом примере личность работника уже не помещается в макроконтекст, скорее, акцентирован микроконтекст выполнения трудовых обязанностей. 


\section{Пример 4. «Белгородский котельщик», № 20 (663) от 22 мая 1970 года.}

Работа слесаря-модельщика очень сложна. Часто над одной деталью он трудится долгие недели, стараясь поточнее и качественнее сделать модель. В иехе № 29 в основном трудятся слесари высокой квалификации. Одним из них является слесарьмодельщик Л. А. Сысоев. Его отличительной чертой является трудолюбие. В канун столетнего юбилея со дня рождения В. И. Ленина, портрет Л. А. Сысоева был вывешен на заводскую Аллею почета.

На снимке: Л. А. Сысоев за работой (фото В. Кузнецова).

Интересный подход к совмещению макро- и микроконтекстов репрезентации личности работников представлен в примере 4: оценочные характеристики выполнения работниками своих трудовых обязанностей коррелируют с идеологическим (столетний юбилей со дня рождения В. И. Ленина) и официально-производственным (размещение портрета на Аллее почета) контекстами.

Пример 5. «Белгородский котельщик», № 27 (670) от10 июля 1970 года.

Марию Федоровну Везенцеву в первом иехе знают как хорошую работнииу. Являясь слесарем-комплектовщиком, она успешно справляется со всеми своими заданиями. Кроме того, Мария Федоровна - активная общественница. Она - заместитель секретаря партийной организаџии цчеха по организаџионным вопросам.

На снимке: М. Ф. Везенцева (фото В. Кузнеиова).

Пример 5 содержит комплексное описание позитивных характеристик передовика: она «хорошая работница» (собственно производственная характеристика), «активная общественница» (общественная деятельность) и «заместитель секретаря» (партийная деятельность).

Характерно, что фотографии и портретные зарисовки или очерки о передовиках также присутствуют и на других полосах газеты (обычно по 2-3 подобных публикации в каждом выпуске). Это обстоятельство, на наш взгляд, указывает на антропоцентричность корпоративного медиадискурса.

За 1999-й год были напечатаны 47 номеров заводской газеты, которая к тому времени выходила уже под названием «Трудовая слава». Корпоративное издание попрежнему выходит один раз в неделю на четырех полосах формата А3. Анализ первых страниц газеты показывает, что зарисовки о людях труда постепенно перестают быть «первополосными». Из 47 номеров они присутствуют на первой полосе лишь в девяти случаях, под рубриками «Слово о заслуженном ветеране», «Твои люди, завод», это составляет 19,1 \%. При этом форма подачи материала несколько меняется: фотография сопровождается более расширенным текстом, по объему это уже примерно четверть полосы. Материалы о людях присутствуют на 2-3 страницах корпоративного издания, но и здесь уже чаще представлены не отдельные личности, а целые трудовые коллективы.

Отметим, что в этот период первые полосы заводской газеты чаще публикуют различные постановления и отчеты с заседаний Совета директоров и собраний акционеров («Трудовая слава» № 7 (1690) от 26 февраля 1999 г., № 10 (1693) от 26 марта 1999 г., № 16 (1699) от 14 мая 1999 г. и др.), а также материалы в рубрике «Производственное совещание» («Трудовая слава» № 3 (1686) от 29 января 1999 г., № 9 (1692) от 19 марта 1999 г., № 17 (1700) от 21 мая 1999 г. и др.). В процентном соотношении это составляет 34 \%. Заголовки публикаций в рубрике «Производственное совещание» нередко включают в себя слово «задача»: «Задача - выполнить план», «Наши дела и задачи» и др. Сами публикации обычно посвящены обсуждению актуальных проблем (состояние трудовой дисциплины, кадровые перемещения, финансовое состояние предприятия, загрузка производств заказами, выполнение договорных обязательств и т. д.). Это позволяет говорить о замещении в корпоративном медиадискурсе антропоцентрической модели на ресурсоцентрическую, суть которой заключается в акцентировании внимания читателя не на личностях работников и их достижениях, а на ресурсах организации, позволяющих ей реализовывать текущую производственную деятельность. 
В 2003 году на базе завода «Белэнергомаш» создано трубопроводное производство Группы предприятий «Энергомаш». Информационно-аналитическое издание ОАО «Энергомашкорпорация» - газета российских энергомашиностроителей «Энергомаш» - издается с 1999 года, печатается в С.-Петербурге, Барнауле, Волгодонске, Екатеринбурге общим тиражом 10 тыс. экземпляров. С января 2003 года в этом печатном издании публикуются и материалы о белгородском предприятии. Газета выходит ежемесячно на восьми полосах формата А3. В течение года в свет вышли 17 номеров (в мае, июне, июле, октябре и декабре - по 2 выпуска), материалы о людях присутствовали на первой полосе лишь однажды - в № 13 (96) за октябрь 2003 года. В процентном соотношении это составляет 7,9 \%. В рубрике «Бизнес-лидеры» дается начало материала под заголовком «Генеральный директор "Энергомашкорпорации" - в числе 100 лучших менеджеров России», окончание публикации - на второй полосе.

В течение года первые полосы информационно-аналитического издания «Энергомаш» систематически занимали материалы официального характера (рубрики «Официально», «В правительстве РФ», «В Совете Федерации РФ»), блиц-интервью с первыми лицами корпорации, «события месяца». Фотографии - преимущественно групповые (заседание коллегии, презентация инженерных центров корпорации, рабочая встреча в Министерстве энергетики России и т. д.). Характерные заголовки этого периода: «Строительство ГТ ТЭЦ координирует коллегия» (№1 (84), 30 января 2003 г.), «Этот пуск принципиально важен!» (№ 4 (87), 17 апреля 2002 г.), «Энергоблок № 1 экзамен сдал!» (№ 5, 15 мая 2003 г.); и с акцентом на географию поставок - «Монгольский контракт» (№ 2, февраль 2003 г.), «Колумбийский контракт умножает заказы» (№ 6 (89), 29 мая 2003 г.), «Турбины отправляются в Колумбию!» (№ 16 (99), 11 декабря 2003 г.). Содержание номеров в целом - как правило, материалы о форсировании хода монтажа и модернизации объектов, сохранении конкурентоспособности, увеличении объемов производства и т.д. Портретных фотографий в газете немало, но они небольшие по размеру, размещены обычно на 3-6 страницах, статичны и однотипны. Все перечисленное также позволяет говорить о постепенном смещении фокуса в корпоративном медиадискурсе с антропоцентрической модели на эффектоцентрическую и ресурсоцентрическую модели.

Современная газета «Энергомаш» (корпоративное издание ООО «Белэнергомаш БЗЭМ») выходит один раз в месяц на четырех полосах формата А3. Наполнена она преимущественно материалами о высоких производственных достижениях предприятия и реализации уникальных проектов. Типичные рубрики в 2014-2019 гг.: «Горизонты сотрудничества», «Визиты», «Новые мощности в строю!», «Проекты», «Импортозамещение» и т.д. Нацеленность на результат прослеживается и в первополосных заголовках: «Цель быть лучшими в своем деле» («Энергомаш», № 12 (15) за декабрь 2014 г.), «Уникальный объект введен в эксплуатацию» («Энергомаш», № 1 (40) за январь 2017 г.), «Реализация уникального проекта потребовала нестандартных решений» («Энергомаш», № 4 (43) за апрель 2017 г.), «Медаль - за разработку и выпуск новой продукции» («Энергомаш», № 11 (62) за ноябрь 2018 г.).

Безусловно, на страницах заводской газеты присутствуют публикации о людях труда, но в целом корпоративный медиадискурс представлен преимущественно «эффектоцентрической» моделью, которая характеризуется тем, что акцент в публикациях сделан не на людях, их условиях труда и достижениях, а на результатах деятельности корпорации и эффективности производства и управления.

Вместе с тем, начиная с 2018 года, коллектив редакции корпоративной газеты озаботился возвращением на первую полосу публикаций о передовиках производства. Планомерная работа в этом направлении уже приносит первые результаты. Если в 2018 году из 12 номеров корпоративного издания рубрика «Передовики производства» с фотографией и рассказом о человеке труда присутствовала на первой полосе в четырех случаях (33,3 \%), то в 2019 году - пять раз (41,6 \%). В этот период материалы о людях труда (с фотографиями) на первой полосе публикуются также в рубриках «Знай наших!» (№ 4 (67) за 
апрель 2019 г., № 8 (71) за август 2019 г.). В общей сложности получается, что антропоцентрическая модель медиадискурса в этот период прослеживается в 58,3 \% случаев, то есть практически в каждом втором номере.

\section{Заключение}

В результате исследования были выявлены три основные аксиологические модели, реализуемые в медиадискурсе издания: антропоцентрическая, ресурсоцентрическая и эффектоцентрическая.

Антропоцентрическая модель характеризуется ценностной акцентуацией репрезентации человека и реализуется с помощью описания позитивных характеристик сотрудников компании в контексте личностных качеств, производственной и общественной деятельности, широким использованием портретных зарисовок и очерков, а также использованием фотографий сотрудников. Эта модель доминирует в выпусках издания 1970-х годов. Ресурсоцентрическая модель обращена к ресурсам организации и реализуется с помощью характерной тематизации материала (состояние трудовой дисциплины, кадровые перемещения, финансовое состояние предприятия, загрузка производств заказами и т.д.), за счёт широкого использования официальной информации и жанра интервью с руководителями компании, а также фотографий, изображающих групповые мероприятия или ресурсы компании. Данная модель доминирует на страницах издания в 1990-х годах. Эффектоцентрическая модель характеризуется тем, что акцент в публикациях сделан на результатах деятельности корпорации и эффективности производства и управления и реализуется за счёт тематического акцентирования достижений компании, количественных показателей деятельности, экономических эффектов и т.д. Эта модель доминирует в газете 2000-2010-х годов.

Таким образом, было подтверждено наше предположение о том, что преобладающая антропоцентрическая модель, в центре которой человек труда и передовики производства, в разные исторические периоды сменялась ресурсо- и эффектоцентрической моделями, ориентированными на коммерческий успех, повышение конкурентоспособности и рост производственных достижений.

В последнее время наблюдается тенденция возврата к антропоцентрической модели корпоративного медиадискурса. В связи с этим мы полагаем уместным указать на следующие закономерности репрезентации человека в корпоративных публикациях, выявленные при анализе материалов 1970-х годов.

Во-первых, внимание читателя акцентируется на личности передовиков, описание качеств которых в положительной тональности сопровождается помещением описания как в макро- (государственно-идеологический и официально-производственный), так и в микроконтекст (собственно производственный).

Во-вторых, личность репрезентируется в аспекте выполнения производственных обязанностей, общественной деятельности и партийной работы. В-третьих, совмещение всех трех типов качеств и двух типов контекста усиливает положительную тональность репрезентации личности работника.

Авторский вклад в развитие исследований внутренних коммуникаций компании состоит в том, что результаты исследования позволяют уточнить методологию анализа медиадискура корпоративных изданий и критерии ценностных моделей медиадискурса, которые включают в себя рубрикацию и тематизацию материала, применённые в публикации риторико-стилистические средства, а также тип, характер и содержание визуального материала, сопровождающего публикацию.

Перспективным направлением исследований корпоративного медиадискурса является определение всего спектра вербальных и визуальных индикаторов антропоцентрической, ресурсоцентрической и эффектоцентрической моделей медиадискурса, а также в 
развитии методологии комплексного анализа репрезентации ценностей компании на вербальном и визуальном уровнях дискурса корпоративного издания.

\section{Список литературы}

1. Агафонов Л.С. 2008. Корпоративная пресса: определения и функции. Вестник Университета Российской академии образования, 5: 74-77.

2. Волкова А.А. 2018. Корпоративные медиа как инструмент формирования лояльности персонала. Медиа Альманах, 1 (84): 49-57.

3. Гвозданная Н. В. 2015. Становление и развитие корпоративного медиадискурса на Западе. Вестник Нижегородского университета им. Н. И. Лобачевского, 4: 214-222.

4. Гвозданная Н.В. 2011. Корпоративная пресса. Российская школа связей с общественностью, 3: 59-70.

5. Добросклонская Т.Г. Медиалингвистика: системный подход к изучению языка СМИ. М., Флинта, 264 с.

6. Играев Б.А. 2012. Корпоративные СМИ и коммуникации в бизнес-процессах. Известия Тульского государственного университета. Гуманитарные науки, 1(1): 15-19.

7. Кожемякин Е.А. 2010. Массовая коммуникация и медиадискурс: к методологии исследования. Научные ведомости Белгородского государственного университета. Серия: Гуманитарныенауки, 2 (73), Вып. 11: 13-21.

8. Лапина Е.В. 2004. Внутрикорпоративная газета как инструмент связей с общественностью. Дисс. ... канд. филол. наук. Тамбов, 246 с.

9. Минаева Л.В. 2018. Корпоративный медиадискурс: риторический анализ. Научные исследования и разработки. Современная коммуникативистика, 7 (2): 8-15.

10. Мурзин Д. Н. 2005. Феномен корпоративной прессы. М., Хроникер, 192 с.

11. Мурзин Д.Н. 2007. Корпоративная пресса: современные типологические концепции. Дисс. ... канд. филол. наук. Москва, 182 с.

12. Нариньяни А.М. 2017. Корпоративная пресса как инструмент маркетинга: основные вопросы издания корпоративных СМИ. Практический маркетинг, 6 (244): 42-47.

13. Олтаржевский Д.О. 2013. Социальная роль корпоративных медиа. Известия Уральского федерального университета. Серия 1: Проблемы образования, науки и культуры, 116 (3): 34-41.

14. Полонский А. В. 2009. Современный медиадискурс: ключевые слова и идеи. В кн.: Русский язык в современном медиапространстве. Междунар. науч.-практ. конф. БелГУ. Отв. ред. А.В. Полонский. Белгород, РОПРЯЛ, БелГУ:151-160.

15. Пригожин А.И. 2007. Дезорганизация: Причины, виды, преодоление. М., Альпина Бизнес Букс, 402 с.

16. Пригожин А.И. 2010. Цели и ценности. Новые методы работы с будущим. М., Дело, 432 с.

17. Ромашова И.П. 2015. Корпоративные СМИ как новые медиа. Коммуникативные исследования, 3 (5): 17-42.

18. Тухватова А. Р. 2007. Особенности развития и функционирования региональных корпоративных СМИ: на примере деятельности изданий и электронных массмедиа ОАО «Татнефть». Дисс. ... канд. филол. наук. Казань, 166 с.

19. Хасянова М. Г. 2013. Значение ценностей в корпоративной культуре. Вестник Кемеровского государственного университета культуры и искусств: журнал теоретических и прикладных исследований, 22 (2): 189-195.

20. Чемякин Ю.В. 2011. Проблемы изучения и преподавания современной российской корпоративной прессы. Известия Уральского государственного университета: Серия 1: Проблемы образования, науки и культуры, 89 (2): 98-105.

\section{References}

1. Agafonov L.S. 2008. Korporativnaya pressa: opredeleniya i funktsii [Corporative press: definition and functions]. Vestnik Universiteta Rossiyskoy akademii obrazovaniya, 5: 74-77.

2. Volkova A.A. 2018. Korporativnye media kak instrument formirovaniya loyal'nosti personala [Corporative media as a tool for formation of personnel loyalty]. Media Al'manakh, 1 (84): 49-57. 
3. Gvozdannaya N. V. 2015. Stanovlenie i razvitie korporativnogo mediadiskursa na Zapade [Development of corporative media discourse in the West]. Vestnik Nizhegorodskogo universiteta im. N.I. Lobachevskogo, 4: 214-222.

4. Gvozdannaya N.V. 2011. Korporativnaya pressa [Corporative press]. Rossiyskaya shkola svyazey s obshchestvennost'yu, 3: 59-70.

5. Dobrosklonskaya T. G. Medialingvistika: sistemnyy podkhod k izucheniyu yazyka SMI [Media linguistics: systemic approach to media language]. M., Flinta, 264 p.

6. Igraev B.A. 2012. Korporativnye SMI i kommunikatsii v biznes-protsessakh [Corporative media and communications in business processes]. Izvestiya Tul'skogo gosudarstvennogo universiteta. Gumanitarnye nauki, 1(1): 15-19.

7. Kozhemyakin E. A. 2010. Massovaya kommunikatsiya i mediadiskurs: k metodologii issledovaniya [Mass communications and media discourse: towards the methodology]. Nauchnye vedomosti Belgorodskogo gosudarstvennogo universiteta. Seriya: Gumanitarnye nauki, 2 (73), V. 11: 13-21.

8. Lapina E.V. 2004. Vnutrikorporativnaya gazeta kak instrument svyazey s obshchestvennost'yu [Corporative newspaper as a tool of public relations]. Diss. ... cand. philology science. Tambov, $246 \mathrm{p}$.

9. Minaeva L.V. 2018. Korporativnyy mediadiskurs: ritoricheskiy analiz [Corporative media discourse: rhetoric analysis]. Nauchnye issledovaniya i razrabotki. Sovremennaya kommunikativistika, 7 (2): 8-15.

10. Murzin D. N. 2005. Fenomen korporativnoy pressy [Phenomenon of corporative press]. M., Khroniker, 192 p.

11. Murzin D. N. 2007. Korporativnaya pressa: sovremennye tipologicheskie kontseptsii [Corporative press: modern typology conceptions]. Diss. ... cand. philology science. Moskva, $182 \mathrm{p}$.

12. Narin'yani A. M. 2017. Korporativnaya pressa kak instrument marketinga: osnovnye voprosy izdaniya korporativnykh SMI [Corporative press as a marketing tool: key issues of corporative media edition]. Prakticheskiy marketing, 6 (244): 42-47.

13. Oltarzhevskiy D.O. 2013. Sotsialnaja rol korporativnykh media [Social role of corporative media]. Izvestiya Ural'skogo federal'nogo universiteta. Seriya 1: Problemy obrazovaniya, nauki i kul'tury - Bulletin of Ural Federal University. Issues of education, science and culture, 116 (3): 34-41.

14. Polonskiy A. V. 2009. Sovremennyy mediadiskurs: klyuchevye slova i idei [Modern media discourse: keywords and ideas]. In: Russkiy yazyk v sovremennom mediaprostranstve [Russian language in the modern media space]. Ed: A.V. Polonskiy. Belgorod, ROPRYaL, BelGU: 151-160.

15. Prigozhin A.I. 2007. Dezorganizatsiya: Prichiny, vidy, preodolenie [Desorganization: reasons, types, overcoming]. Eds. O. Prigozhina, P. Suvorova. M., Al'pina Biznes Buks, 402 p.

16. Prigozhin A.I. 2010. Tseli i tsennosti. Novye metody raboty s budushchim [Goals and values. New ways to work with the future]. M., Delo, $432 \mathrm{p}$.

17. Romashova I.P. 2015. Korporativnye SMI kak novye media [Corporative media as new media]. Kommunikativnye issledovaniya, 3 (5): 17-42.

18. Tukhvatova A. R. 2007. Osobennosti razvitiya i funktsionirovaniya regional'nykh korporativnykh SMI: na primere deyatel'nosti izdaniy i elektronnykh massmedia OAO «Tatneft'» [Features of development and functionnung of corporative media: based on printed and online media of Tatneft]. Diss. ... cand. philology science. Kazan', $166 \mathrm{p}$.

19. Khasyanova M. G. 2013. Znachenie tsennostey v korporativnoy kul'ture [Role of values in corporative culture]. Vestnik Kemerovskogo gosudarstvennogo universiteta kul'tury i iskusstv: zhurnal teoreticheskikh i prikladnykh issledovaniy, 22 (2): 189-195.

20. Chemyakin Yu.V. 2011. Problemy izucheniya i prepodavaniya sovremennoy rossiyskoy korporativnoy pressy [Issues of study and teaching of contemporary corporative media]. Izvestiya Ural'skogo gosudarstvennogo universiteta: Seriya 1: Problemy obrazovaniya, nauki i kul'tury, 89 (2): 98-105.

\section{ИНФОРМАЦИЯ ОБ АВТОРЕ}

Семашкина Надежда Сергеевна, заместитель редактора, ответственный секретарь городской еженедельной газеты «Наш Белгород», аспирант кафедры журналистики института общественных наук и массовых коммуникаций Белгородского национального исследовательского университета, г. Белгород, Россия

\section{INFORMATION ABOUT THE AUTHOR}

Nadezhda S. Semashkina, deputy editor, executive secretary of the city weekly newspaper "Our Belgorod", postgraduate student of the Department of journalism, Institute of social Sciences and mass communications Belgorod national research University, Belgorod, Russia 